\title{
Nodal disease predicts recurrence whereas other traditional factors affect survival in a cohort of South African patients with differentiated thyroid carcinoma
}

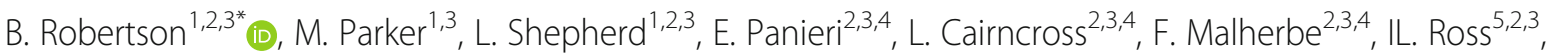

F. Omar ${ }^{6,3}$ and A. Hunter ${ }^{1,2,3}$

\begin{abstract}
Background and aim: Information on patients with differentiated thyroid carcinoma in South Africa is limited. The objective of this study was to review demographics and tumour characteristics in a cohort of patients with differentiated thyroid carcinoma, presenting to Groote Schuur Hospital and evaluate risk factors for recurrence and survival.

Patients and methodology: Retrospective demographic and clinical data were collected on all patients referred between January 2003 and December 2013. Prognostic factors for recurrence free survival and cancer specific survival were assessed using univariate and multivariate analyses.

Results: The total number of patients was 231 . The median age at presentation was 44 years and $82 \%$ were female patients. The pathological sub-types were papillary (60.6\%), follicular (38.9\%) and poorly differentiated (0.5\%). Total thyroidectomy was performed in 191 patients and 30 patients required neck dissections. A total of 171 (74\%) patients received ${ }^{131}$ lodine. The recurrence free and cause specific survival rates at 10 years were 83 and $91 \%$, respectively. Nodal disease at presentation was the only significant risk factor for recurrence $(p<0.001)$ on multivariate analysis. Significant risk factors for cause specific mortality were age $\geq 45$ years $(p=0.006)$, follicular pathology $(p=0.004)$, extra-thyroid extension $(p=0.013)$ and residual tumour $(p=0.004)$.

Conclusions: Consistent with international trends, patients with differentiated thyroid carcinoma treated at Groote Schuur Hospital had a favourable prognosis. The known risk factors associated with recurrence and survival in this South African cohort were consistent with those reported in developed countries.
\end{abstract}

Keywords: Differentiated thyroid carcinoma, South Africa, Prognostic factors, Survival

\section{Introduction}

Differentiated thyroid carcinoma (DTC), although rare, is the most common endocrine tumour. The disease is more frequently observed in women with a ratio of approximately 2.5:1 [1-3]. The National Cancer Registry of South Africa in 2010 reported that the age standardised incidence rate per 100,000 was 1.13 in females and 0.45 in males and DTC accounted for 0.95 and $0.32 \%$ of all cancers in women and men, respectively [3].

\footnotetext{
* Correspondence: Barbara.Robertson@uct.ac.za

${ }^{1}$ Department of Radiation Oncology, Cape Town, South Africa

${ }^{2}$ Groote Schuur Hospital, Cape Town, South Africa

Full list of author information is available at the end of the article
}

Overall, the prognosis is favourable; however, certain features, such as older age, follicular sub-type, larger tumour size, extra-thyroid extension, nodal involvement and metastases are related to poorer outcome [4-9].

There is limited published information on South African patients with differentiated thyroid carcinoma. It is assumed that risk factors that affect prognosis and survival are comparable to those observed in developed countries where most treatment protocols are written. However, it is important to confirm this hypothesis and assess if protocols written in first world countries are applicable to countries in which health resources are limited. In the current study, patient demographics and

(c) The Author(s). 2018 Open Access This article is distributed under the terms of the Creative Commons Attribution 4.0 International License (http://creativecommons.org/licenses/by/4.0/), which permits unrestricted use, distribution, and 
tumour characteristics in a cohort of patients referred to Groote Schuur Hospital were examined and known prognostic factors were evaluated for an effect on survival and recurrence. These results were compared to outcomes published from centres in the developed world.

\section{Patients and methodology}

\section{Data collection}

Groote Schuur Hospital is an academic hospital associated with the University of Cape Town and serves as a referral centre for the majority of the approximately 4,000,000 people, living in the Cape Town metropolitan area.

Retrospective data were collected from hospital records on all patients with differentiated thyroid carcinoma referred to our unit from January 2003 to December 2013, inclusive. Demographic data, pathology and risk factors for recurrence were recorded. For the purposes of this audit, we used the current British Thyroid Association Guidelines published in 2014 to specify the post-operative risk group for recurrence [10]. Stage at presentation was determined using the American Joint Committee on Cancer (AJCC) staging manual $[11,12]$. The extent of surgery, use of ${ }^{131}$ Iodine $\left({ }^{131} \mathrm{I}\right)$, other treatment modalities and responses were also documented.

\section{Treatment and follow up}

Patients were assessed by a multidisciplinary team, comprising specialists from Endocrine Surgery, Radiation Oncology, Nuclear Medicine, Endocrinology and Anatomical Pathology. The British Thyroid Association guidelines published initially in 2002 [13], and updated in 2007 [14], were the basis for our approach to treatment.

In brief, for patients with a tumour size of $\leq 1 \mathrm{~cm}$ and no associated poor prognostic factors, a lobectomy only was performed. For patients with a tumour size of $>1 \mathrm{~cm}$, multifocal tumours and for smaller tumours with risk factors, a total thyroidectomy was performed. Central compartment neck dissections were not routinely performed, however, any neck nodes suspicious for malignancy were removed at surgery. Patients presenting with metastatic cervical nodes outside the central compartment had the relevant node dissection at the time of total thyroidectomy. After total thyroidectomy, ${ }^{131}$ I for ablation was administered and a post-treatment diagnostic scan was performed. Patients who were treated with ${ }^{131} \mathrm{I}$ ablation had a follow-up ${ }^{123}$ I diagnostic scan six to twelve months thereafter, with simultaneous measurements of thyroglobulin and thyroglobulin antibody levels. If there was persistent uptake on the diagnostic scan, therapeutic ${ }^{131} \mathrm{I}$ with higher activity was administered. Patients presenting with metastatic disease with Eastern Cooperative Oncology Group Performance Status (ECOG PS) 0-2 were treated with total thyroidectomy and a combination of external beam radiation. In addition, repeated doses of ${ }^{131} \mathrm{I}$, were administered provided that there was persistent iodine avidity, decreasing thyroglobulin levels and expected clinical benefit. On the other hand, patients with persistent or recurrent disease in the neck that was deemed unresectable and not iodine avid, were treated with external beam radiation.

Once the initial treatment was completed, all patients were prescribed thyroxine for thyroid stimulating hormone (TSH) suppression and were followed up clinically. Patients were also monitored for recurrence using thyroglobulin and thyroglobulin antibody levels. Elevated levels prompted further imaging with ultrasound of the neck, and/or ${ }^{123}$ I diagnostic scans to confirm recurrence. Recurrences were assessed to determine suitability for resection, ${ }^{131}$ I or external beam radiation.

\section{Statistical analysis}

Recurrence free survival (RFS) was calculated from the date of initial surgery to the first recorded date of recurrence. Cause specific survival (CSS) and overall survival (OS) were calculated from the date of surgery to the date of death. For the nine patients (4\%) who did not have surgery, survival was calculated from the date of diagnosis to death. The time-interval between the date of diagnosis and the date of surgery did not differ by more than six weeks. For overall survival, death from any cause was included and for CSS, thyroid cancer-related death, was included. Patients lost to follow-up were censored at the date of the last recorded clinic visit or last contact with the patient.

All statistical analyses were performed using SPSS (Statistical Package for Social Sciences) version 23 (SPSS, Chicago, IL, USA). Survival (RFS, CSS and OS) analysis was completed using the Kaplan-Meier method [15] and survival curves were compared using the log-rank test. A $p$-value of less than 0.05 was accepted as statistically significant and reported $p$-values were not adjusted for multiple testing.

The influence of potential prognostic factors on RFS and CSS was initially investigated using Log-Rank (Mantel-Cox) univariate analysis. Prognostic factors included age, gender, primary tumour stage $(\mathrm{T})$, extra-thyroid extension, pathology, nodal status, residual tumour, metastases and post-operative risk stratification for recurrence. Variables that were identified as significantly associated with survival on univariate analysis were entered into a Cox proportional hazards regression model for multivariate analysis. The backward-stepwise likelihood ratio (LR) procedure for Cox regression was performed and results were reported as relative risk ratios (hazard ratios: HR) and $95 \%$ confidence intervals $(\mathrm{CI})$. In the multivariate analyses, the group of patients with a missing value (unknown) for the prognostic factor evaluated was included with the group that showed a similar survival for that 
Table 1 Patient and tumour characteristics, treatment details

\begin{tabular}{|c|c|}
\hline Characteristic & N (\%) \\
\hline \multicolumn{2}{|l|}{ Gender } \\
\hline Male & $42(18)$ \\
\hline Female & $189(82)$ \\
\hline \multicolumn{2}{|l|}{ Age (years) } \\
\hline Median (range) & $44(9-89)$ \\
\hline \multicolumn{2}{|l|}{ Pathology } \\
\hline Papillary & $140(60.6)$ \\
\hline Follicular & $90(38.9)$ \\
\hline Poorly differentiated & $1(0.5)$ \\
\hline \multicolumn{2}{|l|}{ Tumour size } \\
\hline$\leq 1 \mathrm{~cm}$ & $42(18.2)$ \\
\hline $1-4 \mathrm{~cm}$ & $105(45.5)$ \\
\hline$>4 \mathrm{~cm}$ & $56(24.2)$ \\
\hline Unknown & $28(12.1)$ \\
\hline \multicolumn{2}{|l|}{ T stage } \\
\hline pTX & $20(8.7)$ \\
\hline pT0 & $1(0.4)$ \\
\hline pT1 & $53(22.9)$ \\
\hline pT2 & 79 (34.2) \\
\hline pT3 & $53(22.9)$ \\
\hline pT4 & $25(10.8)$ \\
\hline \multicolumn{2}{|l|}{ Nodal status } \\
\hline NO & $147(63.7)$ \\
\hline N1 & $65(28.1)$ \\
\hline Unknown & $19(8.2)$ \\
\hline \multicolumn{2}{|l|}{ Metastases } \\
\hline MO & $203(88)$ \\
\hline M1 & $23(10)$ \\
\hline Unknown & $5(2)$ \\
\hline
\end{tabular}

Post-operative risk stratification for risk of recurrence (British Thyroid Association Guidelines 2014) [10]

$\begin{array}{ll}\text { High } & 44(19.1) \\ \text { Intermediate } & 98(42.4) \\ \text { Low } & 82(35.5) \\ \text { Unknown } & 7(3) \\ \text { Surgery } & \\ \text { Nil } & 9(4) \\ \text { Lobectomy } & 31(13) \\ \text { Total thyroidectomy } & 161(70) \\ \text { Total thyroidectomy and neck dissection } & 30(13) \\ { }^{31} \text { lodine } & \\ \text { Nil } & 60(26) \\ \text { Ablation } & 171(74) \\ { }^{131} \text { lodine repeated } & 60(26)\end{array}$

Table 1 Patient and tumour characteristics, treatment details (Continued)

\begin{tabular}{ll}
\hline Characteristic & $\mathrm{N}(\%)$ \\
\hline External beam radiation & $9(4)$ \\
Neck, 56-66 Gy & $17(7)$ \\
Palliative & $205(89)$ \\
Nil & \\
Recurrence & $21(9.5)$ \\
Locoregional & $2(0.9)$ \\
Distant & $5(2.2)$ \\
Locoregional and distant & $203(88)$ \\
None & \\
Deaths & $27(11.6)$ \\
Total number of deaths & $16(6.9)$ \\
Deaths due to thyroid cancer &
\end{tabular}

factor. Survival curves where the unknown values were either included or excluded were compared and no significant difference was observed.

\section{Results}

During the assessment period, 231 patients were referred to our unit. The baseline patient and tumour characteristics, as well as staging and initial treatment, are shown in Table 1. There were 189 (82\%) females with a median age of 44 years and an interquartile range (IQR) of 33-56 years. The median age for male patients was 53 (IQR 36-64) years. Seventeen patients (7\%) had an associated cancer that either antedated or occurred subsequently to the development of thyroid cancer, with the most common primary sites being colorectal and breast. Only four patients had significant risk factors for developing thyroid cancer, with three having a positive family history and one patient who underwent whole body radiation for Hodgkin's lymphoma.

The median follow-up period was 57 months. Thirty patients were lost to follow-up and were censored at the last visit or last contact with the patient. The RFS at 10 years was $83 \%$. The CSS and OS at 10 years was 91 and $84 \%$, respectively. For patients who presented with metastases, the 10 year survival was $25 \%$, with a median survival of 27 months.

Twenty-eight patients (12\%) developed recurrence, with 21 having only loco-regional recurrence. Of the patients who had developed recurrence, $60 \%$ presented with clinically obvious recurrence, by way of enlarged neck nodes or bone pain. The remainder were detected by ultrasound of the neck or rising thyroglobulin levels. Surgery was performed for recurrent disease amenable to resection followed by ${ }^{131} \mathrm{I}$ and external beam radiation, where indicated. Of the patients who had developed recurrence, 50\% demonstrated no further evidence of disease following appropriate treatment. 
The prognostic factors evaluated for RFS and CSS are shown in Tables 2 and 3, respectively. Univariate analysis demonstrated that male gender $(p=0.04)$, T4 $(p=0.038$ for $\mathrm{T} 1, p=0.011$ for T2), extra-thyroid extension $(p=0.02)$, nodal involvement $(p=0.004)$ and intermediate $(p=0.02)$, or high $(p=0.05)$ post-operative risk stratification, were significant for recurrence. However, on multivariate analysis

Table 2 Univariate analyses for RFS

\begin{tabular}{llll}
\hline Variable & $N(204)$ & 10 -year & $p$-value \\
RFS \% & (log rank) & $\begin{array}{l}\text { Prognostically } \\
\text { unfavourable } \\
\text { subgroup }\end{array}$ \\
\hline
\end{tabular}

\begin{tabular}{|c|c|c|c|c|}
\hline \multicolumn{5}{|l|}{ Pathology } \\
\hline $\begin{array}{l}\text { Follicular } \\
\text { and Hurthle }\end{array}$ & 74 & 81 & ns & - \\
\hline Papillary & 129 & 77 & & \\
\hline \multicolumn{5}{|l|}{ Gender } \\
\hline Male & 34 & 78 & 0.04 & Male \\
\hline Female & 170 & 81 & & \\
\hline \multicolumn{5}{|l|}{ Age } \\
\hline$<45$ & 109 & 78 & ns & \\
\hline$\geq 45$ & 95 & 79 & & \\
\hline \multicolumn{5}{|l|}{ T stage } \\
\hline TO & 1 & 100 & & \\
\hline $\mathrm{T} 1$ & 49 & 85 & $0.038^{\top}$ & \\
\hline $\mathrm{T} 2$ & 76 & 85 & $0.011^{*}$ & T4 \\
\hline T3 & 48 & 75 & & \\
\hline $\mathrm{T}^{\mathrm{T}_{*}}$ & 16 & 60 & & \\
\hline TX & 14 & 63 & & \\
\hline \multicolumn{5}{|c|}{ Extra-thyroid extension } \\
\hline No & 171 & 87 & $0.02^{*}$ & Extra-thyroid \\
\hline Yes* & 23 & 64 & & extension \\
\hline Unknown & 10 & 53 & & \\
\hline \multicolumn{5}{|l|}{ Nodal status } \\
\hline $\mathrm{NO}^{\top_{*}}$ & 130 & 93 & & N1 \\
\hline N1 & 63 & 76 & $0.004^{*}$ & and \\
\hline NX (unknown) & 11 & 30 & $<0.001^{\top}$ & unknown \\
\hline \multicolumn{5}{|l|}{ Residual tumour } \\
\hline $\mathrm{RO} / 1^{\dagger}$ & 175 & 88 & & \\
\hline $\mathrm{R}^{\top}$ & 15 & 100 & & Unknown \\
\hline Unknown & 14 & 24 & $<0.001^{\dagger}$ & \\
\hline \multicolumn{5}{|c|}{ Post-operative risk stratification for risk of recurrence } \\
\hline High & 17 & 72 & $0.05^{*}$ & High, intermediate \\
\hline Intermediate $^{\dagger}$ & 98 & 74 & $0.02^{*}$ & and \\
\hline Low $^{*}$ & 82 & 90 & & unknown \\
\hline Unknown & 7 & 24 & $0.006^{\dagger} ; 0.001^{*}$ & \\
\hline
\end{tabular}

Symbols denote the associated prognostic variable for each $p$-value. Patients who presented with unresectable primary tumours and distant metastases were excluded $(n=27)$. These patients were not treated with curative intent and therefore could not be included in the recurrence free survival analysis
(Table 4), only nodal disease (HR 4.523, $p<0.001$ ) was independently predictive for recurrence.

For CSS poor prognostic factors on univariate analysis were age $\geq 45$ years $(p<0.001)$, T4 $(p=0.018$ for T3, < 0.01 for T1 and T2), follicular pathological sub-type $(p=0.012)$, extra-thyroid extension $(p<0.001)$, residual tumour $(p<0.001)$, metastases at presentation $(p=$ $0.001)$ and high risk post-operative risk stratification for recurrence $(p<0.001)$. On multivariate analysis for CSS (Table 5) age $\geq 45$ years (HR 22.746, $p=0.006$ ), follicular pathology (HR 5.461, $p=0.004$ ), extra-thyroid extension (HR 5.123, $p=0.013$ ), and residual tumour (HR 24.219, $p=0.004$ ) were independently predictive.

Missing data groups that were found to be significant on univariate analysis for recurrence were nodal status $(p<0.001$, NX vs N0), residual tumour i.e. no documentation on the surgical procedure was available indicating whether the tumour was completely resected or not $(p<0.001$ for $\mathrm{R} 0 / 1$ and R2), and post-operative risk stratification for risk of recurrence $(p=0.001$ for low risk and 0.006 for intermediate risk). For CSS, the significant factors were TX ( $p<0.01$ for T1, 2 and 3), nodal status $(p=0.001$, NX vs N0), extra-thyroid extension $(p<0.001$ for none), and residual tumour ( $p<0.001$ for R0/1).

Of the patients who had a total thyroidectomy and received ${ }^{131}$ I for ablation, 32 (18.7\%) had persistent uptake of ${ }^{123} \mathrm{I}$ on follow-up diagnostic scan and required further ${ }^{131}$ I administration. Nine patients had unresectable residual disease in the neck that was not iodine avid and were treated with external beam radiation to a dose of between 55 and 66 Gy in 2 to 2.4 Gy fractions. For the 23 patients presenting with metastatic disease, 18 (75\%) had a total thyroidectomy followed by ${ }^{131} \mathrm{I}$.

\section{Discussion}

This retrospective review showed that the known prognostic factors for differentiated thyroid carcinoma were relevant in a cohort of South African patients. In addition, the survival rates for our cohort of patients were similar to those observed at other centres. Our CSS was 94 and $91 \%$ at 5 and 10 years, respectively and the RFS was 91 and $83 \%$ for the same periods of observation. Analysis of the SEER database [16], reported a CSS of $98-99 \%$ at 5 years. Single institution reviews from Canada [4] and Germany [17] reported CSS rates at 10 years of 87.3 and $90.3 \%$, respectively. For RFS, Mazzaferri et al. [6, 7] reported 30-35\% recurrence rates with the majority occurring within the first 10 years after treatment.

Follicular carcinoma generally accounts for $15-24 \%$ of all differentiated thyroid carcinomas worldwide [4, 18-21]. However, we observed a higher proportion (35\%) of follicular carcinoma in our patients. As mentioned previously, dietary deficiency of iodine appears to be associated with 
Table 3 Univariate analyses for CS survival

\begin{tabular}{|c|c|c|c|c|}
\hline Variable & N & $\begin{array}{l}\text { 10-year CS } \\
\text { survival \% }\end{array}$ & $\begin{array}{l}p \text {-value } \\
\text { (log rank) }\end{array}$ & $\begin{array}{l}\text { Prognostically } \\
\text { unfavourable } \\
\text { subgroup }\end{array}$ \\
\hline
\end{tabular}

Age

$\begin{array}{lllll}\text { Less than } 25 & 27 & 100 & 0.01^{*} & 56-65 \\ 26-35 & 44 & 90 & 0.002^{*} & \\ 36-45 & 52 & 98 & 0.003^{*} \\ 46-55 & 40 & 94 & 0.03^{*}\end{array}$

$\begin{array}{lll}56-65^{*} & 41 & 72 \\ 66-75 & 23 & 86 \\ \text { Greater than } 76 & 4 & 45 \\ \text { Age } & & \end{array}$$$
<45
$$$$
\geq 45
$$

Gender

$$
\text { Male }
$$

Female

T stage

$\mathrm{TO}$
$\mathrm{T}^{T_{*}}$
$\mathrm{~T} 2^{T_{*}}$
$\mathrm{~T}^{\# *}$

T4

TX

Extra-thyroid extension

$\mathrm{No}^{+}$

Unknown

Pathology

Follicular and Hurthle $\quad 90 \quad 82$

Papillary

Nodal status

$\mathrm{NO}^{+}$

N1

NX (unknown)

Residual tumour

R0/1 ${ }^{\dagger}$
R2
n/a
Unknown

Metastases

$\begin{array}{lll}\text { M0 } & 203 & 96 \\ \text { M1* } & 23 & 54 \\ \text { MX (unknown) } & 5 & 67\end{array}$

Table 3 Univariate analyses for CS survival (Continued)

\begin{tabular}{lccll}
\hline Variable & $N$ & $\begin{array}{l}\text { 10-year CS } \\
\text { survival \% }\end{array}$ & $\begin{array}{l}p \text {-value } \\
\text { (log rank) }\end{array}$ & $\begin{array}{l}\text { Prognostically } \\
\text { unfavourable } \\
\text { subgroup }\end{array}$ \\
\hline $\begin{array}{l}\text { Post-operative risk stratification for risk of recurrence } \\
\text { High* }\end{array}$ & 44 & 46 & & \\
Intermediate & 98 & 91 & $<0.001^{*}$ & High \\
Low & 82 & 96 & $<0.001^{*}$ & \\
Unknown & 7 & 80 & & \\
\hline \multicolumn{4}{l}{ Symbols denote the associated prognostic variable for each $p$-value }
\end{tabular}

an increased risk of follicular carcinoma [22]. Prior to 1995, when legislation in South Africa required the addition of potassium iodate to table salt, a study assessing goiter prevalence and urine iodine concentration in children revealed evidence of iodine deficiency in the Mpumalanga, Northern Province and Eastern Cape provinces of South Africa [23]. Although the Western Cape was not included in the study, it is feasible that dietary deficiency may account for the higher percentage of follicular carcinomas in our patients.

We compared the tumour size and presence of cervical node metastases of our patient group at presentation with those described in retrospective reviews from North America. Reports on tumour size from a number of different studies showed a wide variation in tumour size. An analysis of relevant information from the SEER database from 1988 to 2009 by Krook et al. [16] indicated that $26.8 \%$ of patients had tumour sizes of $<1 \mathrm{~cm}$ and $11.98 \%$ of patients had tumour sizes of $\geq 4 \mathrm{~cm}$. Investigators from Princess Margaret Hospital (PMH) reported that only 9\% of patients had tumour sizes of $<1 \mathrm{~cm}$ and $29 \%$ had tumour sizes of $>4 \mathrm{~cm}$ [4]. A significant proportion of patients in both reviews and those in a study from Turkey [24] had tumour sizes ranging from 1 to $4 \mathrm{~cm}$, which was consistent with the size range observed in our patients. Nodal metastases were present in $28.1 \%$ of our patients in comparison to other reports, in which it ranged from 10.5 to $50 \%[5,16,18,19,25]$. The proportion of patients presenting with distant metastases was $10 \%$, which is similar to the $9 \%$ reported from PMH [4], but higher than the $4 \%$ reported from the SEER database $[5,18]$.

There are several prognostic factors known to influence both recurrence and mortality in patients with differentiated thyroid carcinoma. The patient-related factors include age $[4,5,7,16,17,20,25,26]$ and gender, the latter being reported in a limited number of studies $[4,16,25,26]$. The tumour-related factors include pathological sub-type, size of the primary tumour, lymph node metastases, extra thyroid extension, gross residual tumour and distant metastases $[4,5,16,17,20,25,26]$. These factors were reviewed in our cohort and, consistent with most other series, our study demonstrated similar prognostic factors for RFS and CSS on univariate analysis. 
Table 4 Multivariate analyses for RFS

\begin{tabular}{llllll}
\hline Variable & Description & Parameter estimate & Standard error & $p$-value & HR (95\% Cl) \\
\hline T stage & T4 vs T0-3 & 0.738 & 0.490 & 0.132 & $2.091(0.800-5.464)$ \\
Extra-thyroid extension & Yes vs no & 0.411 & 0.548 & 0.453 & $1.508(0.515-4.415)$ \\
Gender & Male vs female & -0.700 & 0.425 & 0.100 & $0.496(0.216-1.142)$ \\
Nodal status & Present vs none & 1.509 & 0.408 & $<0.001^{*}$ & $4.523(2.032-10.070)$ \\
\hline
\end{tabular}

*denotes statistically significant $p$ values

Groups characterised by missing data for certain tumour factors were assessed independently in the univariate analysis and significant associations with poorer prognosis were observed. Some undetermined factor may be responsible for the poorer prognosis however such associations may reflect inadequate management as a result of the limited information available for this group of patients. It is therefore important to ensure all prognostic variables are available and evaluated when making post-operative decisions.

For tumour recurrence the only factor that was independently predictive on multivariate analysis was the presence of nodal metastases. For mortality from thyroid carcinoma, significant factors found to be independently associated were age $\geq 45$ years, follicular pathology, extra-thyroid extension and residual tumour. As stated previously, for the multivariate analysis, the groups of patients with missing data for each prognostic factor were included with the group that had a similar survival. In general, this was the prognostically unfavourable subgroup. Overall, distinct factors were found to affect recurrence and mortality.

Multiple studies have reported that the patient's age at diagnosis affects prognosis $[4-6,16,17,20,25,26]$. It is notable that differentiated thyroid carcinoma is the only cancer in the AJCC staging system in which age is incorporated into the stage. We followed the AJCC 6th and 7th editions, using 45 years as the cut-off age and found that there was a significantly higher risk of mortality from thyroid cancer for those $\geq 45$ years $[11,12]$. A recent analysis by Nixon et al. [27] of over 9000 patients, compared the disease specific survival for patients aged
$<45$ years with those aged $<55$ years. The authors showed that $12 \%$ of patients could be down-staged and proposed that the cut-off age of 45 years be increased to 55 years for staging [27]. The recently published AJCC 8 th edition has changed the age for poor prognosis from 45 to 55 years [28]. Age did not affect the risk of recurrence in our cohort.

Male patients have been reported to have a worse prognosis in some studies $[4,6,16]$. In our patients gender, although significant for recurrence on univariate analysis, was not significant for recurrence or survival on multivariate analysis.

Nodal involvement was a significant determinant of recurrence in our cohort. In the previous AJCC staging systems, the presence of pathological nodes affected the stage in patients aged 45 years and older with the presence of nodal metastases outside level VI, placing patients into the stage IV group. Patients aged less than 45 years, regardless of the presence of nodal metastases were all considered to be stage I. Brierly et al. [4] showed that the presence of nodal metastases significantly affect recurrence but not cause-specific survival. However, a publication by Adam et al. [9] reviewing the National Cancer Database (NCDB) and SEER has shown that nodal involvement, as well as the number of nodes involved, does affect survival in patients with papillary carcinoma who are younger than 45 years of age. Although the effect on overall survival at 10 years was relatively small, namely, $98.2 \%$ versus $97.8 \%$ for the NCBD and 98.7\% versus $98.5 \%$ for SEER (HR for NCDB 1.32, $p=$ 0.021 , HR for SEER 1.29, $p=0.006$ ), they suggested that, with the increasing incidence of papillary thyroid

Table 5 Multivariate analyses for CSS

\begin{tabular}{llllll}
\hline Variable & Description & Parameter estimate & Standard error & $p$-value & $\mathrm{HR}(95 \% \mathrm{Cl})$ \\
\hline T stage & T4 vs other & 0.079 & 1.141 & 0.945 & $1.082(0.116-10.119)$ \\
Metastatic disease at presentation & Present vs none & 0.571 & 0.590 & 0.333 & $1.770(0.557-5.628)$ \\
Extra-thyroid extension & Yes vs no & 1.634 & 0.657 & $0.013^{*}$ & $5.123(1.414-18.563)$ \\
Pathology & Follicular & 1.698 & 0.586 & $0.004^{*}$ & $5.461(1.730-17.236)$ \\
& vs other & & & $0.004^{*}$ & $24.219(2.721-215.549)$ \\
Residual tumour & R2 vs other & 3.187 & 1.115 & $0.006^{*}$ & $22.746(2.497-207.190)$ \\
Age & $<45$ vs $\geq 45$ & 3.124 & 1.127 & &
\end{tabular}

*denotes statistically significant $p$ values

${ }^{a}$ with Hurthle 
carcinoma in the USA, the absolute number of deaths could be significant [9].

Our patients with follicular carcinoma had a significantly higher risk of mortality than those with papillary carcinoma. This is consistent with reviews by Hundahl et al. [19], Mazzaferri et al. [7] and Shaha et al. [25]. In addition, extra-thyroid extension and gross residual tumour have been shown to affect prognosis $[4,18,25,26]$. For our patients, none of these factors could be shown to predict for recurrence, but were significant for mortality. Since the approach to treatment was similar for the majority of patients we did not examine the effect of the extent of surgery or ${ }^{131}$ I ablation on recurrence or survival. Biological agents such as sorafenib and lenvatinib were not available for patients with iodine refractory disease.

Of the entire group, only 28 patients $(12.5 \%)$ recurred and were treated with either surgery, 131-iodine, external beam radiation or a combination of these modalities. The median time to recurrence was 32 months although one patient developed recurrence 20 years after initial treatment. Notably, Mazzaferri et al. [7] reported recurrences in $30 \%$ of patients up to approximately 35 years after initial treatment. The majority, however, occurred within the first ten years and only 15\% died after developing recurrence. Of our patients who developed recurrence, $50 \%$ had no evidence of disease following treatment for the recurrence. This outcome emphasises that patients require careful monitoring to detect early potentially curative recurrence.

The British Thyroid Association Guidelines published in 2002 [13] and updated in 2007 [14] recommended that all patients with a tumour size $>1 \mathrm{~cm}$ should be treated with total thyroidectomy, ${ }^{131} \mathrm{I}$ ablation and TSH suppression. We followed these guidelines for this cohort of patients. In 2014 the guidelines were updated with identification of factors other than tumour size being taken into account to give a more personalised approach to patient management [10]. These updated guidelines have allowed a more conservative approach to surgery and ${ }^{131} \mathrm{I}$ ablation in many of our current patients.

\section{Conclusions}

In summary, we observed a higher proportion of patients with follicular carcinoma in our cohort when compared with other centres and this may be a result of iodine deficiency in the diet. The stage at presentation, prognostic factors, RFS and CSS were similar to reports from first world centres. Of the reported factors that affect prognosis in patients with differentiated thyroid cancer, only the presence of nodal metastases predicted for recurrence, while age $\geq 45$ years, follicular pathology, extra-thyroid extension and residual tumour predicted for CSS. Our results demonstrate that, in a resource constrained setting, patients with differentiated thyroid carcinoma have a favourable prognosis with multidisciplinary team management and adherence to recognised treatment protocols. Since the current British Thyroid Association guidelines [10] allow for a less aggressive and more tailored approach to treatment it is important to continue to monitor our patients to ensure that similar outcomes are achieved.

\section{Abbreviations \\ ${ }^{131}$ I: ${ }^{131}$ Iodine; AJCC: American Joint Committee on Cancer; Cl: Confidence intervals; CSS: Cause specific survival; DTC: Differentiated thyroid carcinoma; ECOG: Eastern Cooperative Oncology Group; Gy: Gray; HR: Hazard ratio; IQR: Interquartile range; LR: Likelihood ratio; NCDB: National cancer database; OS: Overall survival; PMH: Princess Margaret Hospital; PS: Performance status; RFS: Recurrence free survival; SEER: Surveillance, Epidemiology, and End Results; SPSS: Statistical package for social sciences; T: Primary tumour; TSH: Thyroid stimulating hormone; USA: United States of America}

\section{Acknowledgements}

Ian Robertson BSc (Hons) Elec Eng, for the statistical analysis.

Funding

None

Availability of data and materials

The datasets used and/or analysed during the current study are available from the corresponding author on reasonable request.

\section{Consent for participation}

Consent for participation was not required as the study was a retrospective review.

\section{Authors' contributions}

BR designed the study and accessed the data. BR, MP and ILR analysed the data and developed the manuscript. All authors reviewed and approved the final manuscript.

\section{Ethics approval and consent to participate}

The study was approved by the University of Cape Town, Faculty of Health Sciences Human Research Ethics Committee and by the Western Cape Health Research Committee.

\section{Consent for publication}

Not applicable

\section{Competing interests}

The authors declare that they have no competing interests.

\section{Publisher's Note}

Springer Nature remains neutral with regard to jurisdictional claims in published maps and institutional affiliations.

\section{Author details}

${ }^{1}$ Department of Radiation Oncology, Cape Town, South Africa. ${ }^{2}$ Groote Schuur Hospital, Cape Town, South Africa. ${ }^{3}$ University of Cape Town, Cape Town, South Africa. ${ }^{4}$ Department of Surgery, Cape Town, South Africa. ${ }^{5}$ Department of Medicine, Cape Town, South Africa. ${ }^{6}$ Division of Chemical Pathology, Cape Town, South Africa.

Received: 17 July 2018 Accepted: 31 October 2018

Published online: 19 November 2018

\section{References}

1. Thyroid cancer incidence statistics. Cancer Research UK. 2016. http://www. cancerresearchuk.org/health-professional/thyroid-cancer-incidence-statistics\# heading-Zero. Accessed 17 Feb 2016.

2. Howlader N, Noone AM, Krapcho M, Garshell J, Miller D, Bishop K, et al., editors. SEER cancer statistics review, 1975-2012, National Cancer Institute. Bethesda, MD, http://seer.cancer.gov/csr/1975_2012/, based on November 
2014 SEER data submission, posted to the SEER web site, April 2015 Accessed 7 July 2016.

3. National Health Laboratory Service (NHLS). National Cancer Registry South Africa. 2010. www.nioh.ac.za/wp-content/uploads/2018/03/NCR-2010-results. pdf. Accessed 11 Nov 2015.

4. Brierley J, Tsang R, Panzarella T, Bana N. Prognostic factors and the effect of treatment with radioactive iodine and external beam radiation on patients with differentiated thyroid cancer seen at a single institution over 40 years. Clin Endocrinol. 2005:63(4):418-27.

5. Zaydfudim V, Feurer ID, Griffin MR, Phay JE. The impact of lymph node involvement on survival in patients with papillary and follicular thyroid carcinoma. Surgery. 2008;144(6):1070-7 discussion 77-8.

6. Mazzaferri EL, Jhiang SM. Long-term impact of initial surgical and medical therapy on papillary and follicular thyroid cancer. Am J Med. 1994;97(5): 418-28.

7. Mazzaferri EL. An overview of the management of papillary and follicular thyroid carcinoma. Thyroid. 1999;9(5):421-7.

8. Shah JP, Loree TR, Dharker D, Strong EW, Begg C, Vlamis V. Prognostic factors in differentiated carcinoma of the thyroid gland. Am J Surg. 1992; 164(6):658-61.

9. Adam MA, Pura J, Goffredo P, Dinan MA, Reed SD, Scheri RP, et al. Presence and number of lymph node metastases are associated with compromised survival for patients younger than age 45 years with papillary thyroid cancer. J Clin Oncol. 2015;33(21):2370-5.

10. Perros P, Boelaert K, Colley S, Evans C, Evans RM, Gerrard GE, et al. Guidelines for the management of thyroid cancer. Clin Endocrinol. 2014; 81(Suppl 1):1-122.

11. Thyroid. In: Greene FL, Page DL, Fleming ID, Fritz AG, Balch CM, Haller DG et. al. editors. AJCC Cancer Staging Manual. 6th ed. New York: SpringerVerlag; 2002. p. 77-87.

12. Thyroid. In: Edge SB, Byrd DR, Compton CC, Fritz AG, Greene FL, Trotti A editors. AJCC Cancer Staging Manual. 7th ed. New York: Springer-Verlag; 2010. p. 111-22.

13. Harris PE. The management of thyroid cancer in adults: review of new guidelines. Clin Med (Lond). 2002;2(2):144-6.

14. British Thyroid Association, Royal College of Physicians. Guidelines for the management of thyroid cancer. In: Perros P, Clarke S, Franklyn J, editors. Report of the thyroid Cancer guidelines update group. 2nd ed. London: Royal College of Physicians; 2007.

15. Kaplan EL, Meier P. Nonparametric estimation from incomplete observations. J Am Stat Assoc. 1958;53(282):457-81.

16. Krook KA, Fedewa SA, Chen AY. Prognostic indicators in well-differentiated thyroid carcinoma when controlling for stage and treatment. Laryngoscope. 2015:125(4):1021-7.

17. Eichhorn W, Tabler H, Lippold R, Lochmann M, Schreckenberger M, Bartenstein P. Prognostic factors determining long-term survival in welldifferentiated thyroid cancer: an analysis of four hundred eighty-four patients undergoing therapy and aftercare at the same institution. Thyroid. 2003;13(10):949-58.

18. Gilliland FD, Hunt WC, Morris DM, Key CR. Prognostic factors for thyroid carcinoma. A population-based study of 15,698 cases from the Surveillance, Epidemiology and End Results (SEER) program 1973-1991. Cancer. 1997; 79(3):564-73.

19. Hundahl SA, Fleming ID, Fremgen AM, Menck HR. A national cancer data base report on 53,856 cases of thyroid carcinoma treated in the U.S., 19851995. Cancer. 1998;83(12):2638-48.

20. Amin A, Younis G, Sayed K, Saeed Z. Cervical lymph node metastasis in differentiated thyroid carcinoma: does it have an impact on disease-related morbid events? Nucl Med Commun. 2015;36(2):120-4.

21. Aboelnaga EM, Ahmed RA. Difference between papillary and follicular thyroid carcinoma outcomes: an experience from Egyptian institution. Cancer Biol Med. 2015;12(1):53-9.

22. Dal Maso L, Bosetti C, La Vecchia C, Franceschi S. Risk factors for thyroid cancer: an epidemiological review focused on nutritional factors. Cancer Causes Control. 2009;20(1):75-86

23. Kalk WJ, Paiker J, Van Arb M, Pick W. Dietary iodine deficiency in South Africa. Surveys before the introduction of universal salt iodisation. S Afr Med J. 1998:88:357-8

24. Erol V, Makay O, Icoz G, Kose T, Yararbas U, Kumanlioglu K, et al. Prognostic factors of survival and recurrence pattern in differentiated thyroid cancer: a retrospective study from Western Turkey. Endocr Regul. 2014;48(4):173-81.
25. Shaha AR. Implications of prognostic factors and risk groups in the management of differentiated thyroid cancer. Laryngoscope. 2004;114(3): 393-402.

26. Mazzaferri EL, Kloos RT. Current approaches to primary therapy for papillary and follicular thyroid cancer. J Clin Endocrinol Metab. 2001;86(4):1447-63.

27. Nixon IJ, Wang LY, Migliacci JC, Eskander A, Campbell MJ, Aniss A, et al. An international multi-institutional validation of age 55 years as a cutoff for risk stratification in the AJCC/UICC staging system for well-differentiated thyroid cancer. Thyroid. 2016;26(3):373-80.

28. Thyroid. In: Amin MB, Edge SB, Greene FL, Byrd DR, Brookland RK, Washington MK et.al. editors. AJCC Cancer Staging Manual. 8th ed. New York: Springer; 2017. p. 873-90.
Ready to submit your research? Choose BMC and benefit from:

- fast, convenient online submission

- thorough peer review by experienced researchers in your field

- rapid publication on acceptance

- support for research data, including large and complex data types

- gold Open Access which fosters wider collaboration and increased citations

- maximum visibility for your research: over $100 \mathrm{M}$ website views per year

At BMC, research is always in progress.

Learn more biomedcentral.com/submissions 